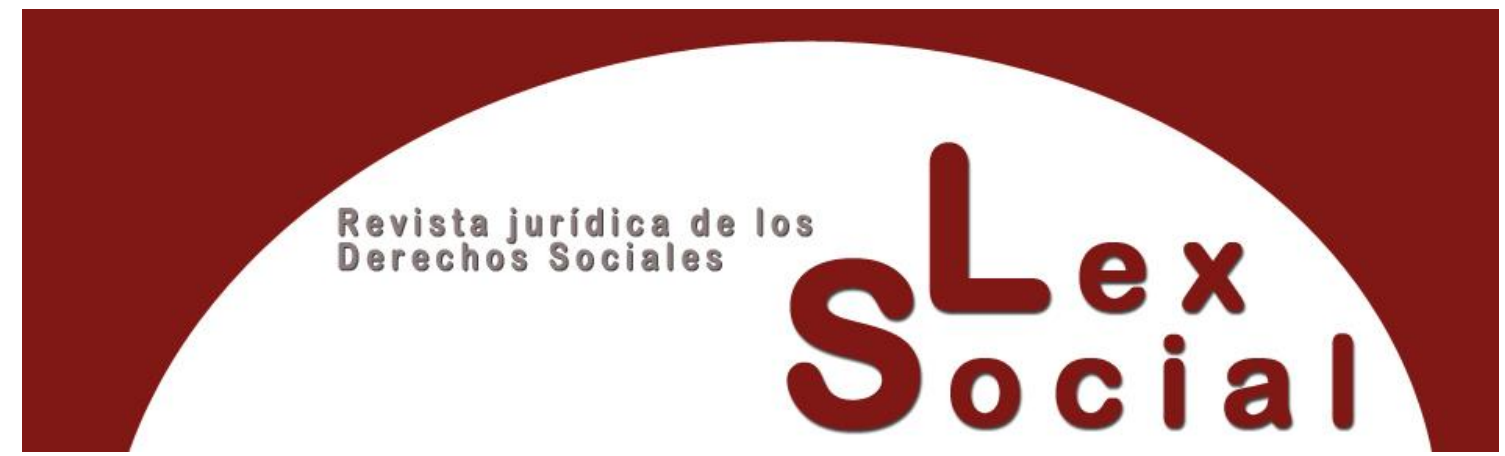

\title{
A VUELTAS CON LA SUCESIÓN DE EMPRESA. AHORA, POR TRANSMISIÓN DE CLIENTELA
}

\section{AROUND THE BUSINESS SUCCESSION. NOW, BY CUSTOMER TRANSMISSION}

RAQUEL POQUET CATALÁ

Profesora asociada (acreditada TU) de la Universidad de Valencia http://orcid.org/0000-0001-9606-8832

Cómo citar este trabajo: Poquet Catalá, R. (2022). A vueltas con la sucesión de empresa. Ahora,por transmisión de clientela. Lex Social, Revista De Derechos Sociales 12 (1), pp. 18-36. https://doi.org/10.46661/lexsocial.6322

\section{RESUMEN}

En este trabajo se realiza un análisis de una posible nueva modalidad de sucesión de empresa, cual es, la sucesión por transmisión de clientela. Para ello, se realiza una breve configuración de la sucesión de empresa, y de los diferentes tipos que existen, analizando la doctrina judicial y jurisprudencial, tanto nacional como comunitaria, que han ido modulando esta institución jurídica. En el caso de la sucesión por transmisión de clientela, el elemento que da lugar a la aplicación del art. 44 ET es simplemente que existe una transmisión de los clientes, sin que sea necesario que tenga lugar también una transmisión de elementos patrimoniales, materiales o inmateriales.

Palabras Clave: sucesión de empresa, transmisión, clientela, subrogación.

\section{Abstract}

In this work, it is carried out an analysis of a possible new type of company succession, which is, the succession by transfer of customers. For this, it is realized

\section{(c) ) EY-NC-SA}


a brief configuration of the succession of the company, and of the different types that exist, analyzing the judicial and jurisprudential doctrine, both national and community, that have been modulating this legal institution. In the case of succession by transmission of customers, the element that gives rise to the application of art. $44 \mathrm{ET}$ is simply that there is a transmission of customers, without it being necessary for a transmission of assets, tangible or intangible, to also take place.

KEYWORDS: company succession, transmission, customers, subrogation.

SUMARIO

\section{Introducción}

II. Sucesión de empresas. Fundamento y finalidad

III. Modalidades de sucesión de empresa

1. Sucesión de empresa legal

2. Sucesión de plantillas

3. Sucesión convencional

4. Sucesión por pliegos

5. Sucesión de empresa por transmisión de clientela

IV. A modo de reflexión final

Bibliografía

\section{Introducción}

El régimen jurídico del art. 44 ET previsto para la sucesión de empresas establece un conjunto de previsiones importantes para las personas trabajadoras afectadas que determinan la necesidad de realizar un análisis profundo de qué debe entenderse por sucesión de empresas.

Ante la falta de una concreción más clara en el precepto estatutario, ha sido la doctrina judicial y jurisprudencial las que han ido perfilando los supuestos que cabe entender como sucesión de empresas. Hasta ahora se había hecho referencia a la transmisión de medios materiales, tales como infraestructura, maquinaria, herramientas, mobiliario, o vehículos, entre otros, así como también a la transmisión de elementos inmateriales, tales como software, y también elementos personales, como la transmisión de la plantilla. No obstante, no se había planteado hasta ahora la posibilidad de que la transmisión de la clientela fuera indicio suficiente para determinar la sucesión de empresa. 
No es la primera vez que contamos con pronunciamientos judiciales al respecto, pues ya existe una doctrina judicial comunitaria al respecto $^{1}$, pero sí que tenemos un pronunciamiento judicial español. De ahí, la necesidad de realizar un análisis de esta nueva modalidad de transmisión de empresa.

No cabe duda que la clientela es el activo más importante de una empresa, pues sin ella, el negocio no existe.

\section{Sucesión de empresas. Fundamento y finalidad}

La sucesión de empresas queda regulada, como es conocido, en el art. 44 ET, precepto que traspuso la Directiva 2001/23/CE, de 12 de marzo, aunque con algunos atisbos y diferencias interpretativas.

La sucesión de empresas es una institución jurídica que tiene como fin mantener la estabilidad en el empleo cuando una empresa, centro de trabajo o unidad productiva autónoma, o una parte de los anteriores, se transmite a otra persona física o jurídica.

Como señala un sector doctrinal, los objetivos de esta figura jurídica son: "1) Garantizar que las novaciones empresariales no afectan a la continuidad de los contratos de trabajo. 2) Implicar al nuevo titular de la empresa en el cumplimiento de las obligaciones preexistentes (subrogación en la posición deudora). 3) Contar con los representantes de los trabajadores e informar a estos acerca de las variaciones. 4) Clarificar los efectos del cambio de empleador sobre diversas instituciones (órganos representativos, convenio aplicable). 5) Trasponer a nuestro ordenamiento las exigencias del Derecho comunitario. 6) En general, evitar el fraude a los derechos de los trabajadores y garantizarlos adecuadamente",2.

Con esta institución jurídica se trata, en fin, de conservar el empleo de las personas trabajadoras afectadas mediante la obligación de subrogación en la plantilla de la empresa cedente por parte de la empresa cesionaria. En palabras de la doctrina "una regla práctica que ayude a comprender la idea latente en la norma es la de que si el negocio jurídico interempresarial no afecta a la actividad de los empleados tampoco su vinculación laboral ha de verse afectada; si lo transmitido posee enjundia bastante como para arrastrar consigo al trabajador; éste ha de verse protegido"3.

\section{Modalidades de sucesión de empresa}

En principio, la transmisión de empresa puede tener lugar por diversos elementos, ya sea propiamente el elemento subjetivo, esto es, el cambio de titularidad, o el elemento

\footnotetext{
${ }^{1}$ SSTJUE de 20 de noviembre de 2003, C-340/2001, Asunto Abler; de 26 de noviembre de 2015, C509/2014, Asunto ADIF; de 8 de mayo de 2019, C-194/2018, asunto Dodic.

${ }^{2}$ Sempere Navarro, Antonio Vicente, "Un comentario al art. 44 del Estatuto de los Trabajadores", Aranzadi Social, núm. 9, 2014, p. 2.

${ }^{3}$ Sempere Navarro, Antonio Vicente, "Un comentario al art. 44... op. cit., p. 4.
} 
objetivo, esto es, por transmisión de los elementos productivos que permitan la continuidad de la actividad empresarial.

En relación con el elemento subjetivo, la doctrina atribuye "capacidad transmisiva a cualquier negocio jurídico o situación que suponga un cambio en la posición jurídica del empresario, al margen de que dicho cambio tenga o no carácter voluntario" ". Las vías de transmisión que dan lugar a la aparición de este elemento subjetivo son varias, tales como, compraventa, cesión, donación, arrendamiento de industria o de negocio, cambio de empresa prestadora de servicios en sucesión de contratas, reversión, ejecución hipotecaria de un inmueble en el que se desarrolla una actividad económica y posterior toma de posición de todos los elementos necesarios para afectar la actividad, herencia...

El elemento objetivo, esto es, la unidad productiva objeto de sucesión, debe, en principio, según la doctrina judicial comunitaria ${ }^{5}$, existir con anterioridad a que tenga lugar la transmisión. Sin embargo, se ha admitido que, aunque la unidad productiva autónoma no preexista a la transmisión con autonomía funcional suficiente, el Derecho nacional del Estado miembro pueda otorgar las garantías de sucesión de empresa que considere convenientes, pues la legislación nacional puede mejorar las previsiones de la Directiva 2001/23/CE. Este aspecto no es baladí, especialmente, en aquellos casos en los que se haya encapsulado la unidad productiva autónoma de manera artificial y, especialmente, cuando no exista un motivo claro por el que se haya agrupado un conglomerado de medios materiales, inmateriales, personales antes de la sucesión, esto es, casos en los que esa unión de elementos no tenga relación clara con la actividad transmitida ${ }^{6}$.

Sin embargo, sí que debe aceptarse que existe sucesión de empresas cuando se decide externalizar una unidad de negocio o unidad productiva que se encuentre repartida en distintas sociedades del grupo de empresas que tiene el papel de cedente. En este sentido, se ha estimado que existe sucesión de empresas por cumplirse el requisito de la preexistencia de la unidad productiva cuando, en el caso de externalización de plataformas de gestión y recuperación de créditos de entidades bancarias, queda acreditado que la actividad de recuperaciones se realizaba de forma expresamente ordenada y organizada por la entidad bancaria; existía una estructura organizativa; estaba estructurada territorialmente y en actividades; la actividad estaba jerárquicamente organizada; y se abona una cantidad considerable de dinero por esa plataforma de la entidad bancaria. Por tanto, "la prueba nos acredita que el banco vende la gestión de recobro de una parte muy relevante de su cartera de impagados, todos los bienes materiales precisos para llevarla a cabo (ordenadores, mobiliario, etc) y al personal

\footnotetext{
${ }^{4}$ Mercader Uguina, Jesús Rafael, "Comentario al artículo 44 ET”, en Cruz Villalón, Jesús, García-Perrote Escartín, Ignacio, Goerlich Peset, José María, Mercader Uguina, Jesús Rafael, (Dirs.), Comentarios al Estatuto de los Trabajadores, Valladolid, Lex Nova, 2014, p. 504.

${ }^{5}$ STJUE de 27 de febrero de 2015, Amatori, Asunto 458/2012, que señala que "por consiguiente, si en el asunto principal, resultara que la unidad transferida de que se trata no disponía, con anterioridad a la transmisión, de una autonomía funcional suficiente, lo que corresponde comprobar al órgano jurisdiccional remitente, tal transmisión no estaría comprendida en el ámbito de aplicación de la Directiva 2001/23. En tales circunstancias no existiría la obligación que se deriva de dicha Directiva de mantener los derechos de los trabajadores transmitidos".

${ }^{6}$ Martínez Saldaña, David, (Coord.), La sucesión de empresas, Cizur Menor, Lex Nova, 2016, p. 117.
} 
dedicado a la realización de dicha actividad. Y esa venta se vincula de forma inexorable a la prestación del contrato de servicios por el que Lindorff gestionará el recobro (directamente y acudiendo a la contratación de abogados y procuradores, tal como en este mismo sentido operaba antes el banco) y recibirá por ello un precio con el que amortizará el coste de la compra de la gestión de la deuda, atenderá los gastos de explotación y obtendrá su beneficio empresarial"7.

No obstante, esta teoría no es tan sencilla en la realidad empresarial, donde existen una multitud de diferentes situaciones que conducen a la necesidad de matizar y analizar caso por caso para determinar su configuración como sucesión de empresa, es decir, analizar en cada caso y de forma global, las circunstancias concurrentes, para determinar cuál es el núcleo que define la entidad económica sobre la que se produce el cambio de titularidad $^{8}$. No existe una regulación normativa que determine qué elementos son los que han de ser transmitidos para determinar la existencia o no de transmisión y, por consiguiente, la subrogación legal. De ahí, la necesidad de determinar si el elemento transmitido tiene suficiente entidad económica como para entender que se transmite la empresa, y con ello, la plantilla. El TJUE parte del principio de seguridad en el empleo, esto es, de una flexibilidad para responder al objetivo de protección de las personas trabajadoras ${ }^{9}$. Esta posición de la doctrina judicial comunitaria ha sido flexibilizada ampliando los objetos de transmisión y adoptando una posición amplia en torno al concepto de entidad económica.

Según la doctrina pueden diferenciarse los siguientes supuestos de subrogación: la sucesión de empresa propiamente dicha; la sucesión de plantillas; la subrogación por convenio colectivo; y la subrogación por pliegos. Adicionalmente a estas modalidades, cabría incluir, en su caso, la sucesión de clientela, supuesto que será analizado en último lugar.

Por otro lado, también puede diferenciarse según si se trata de una actividad materializada, esto es, con activos tangibles y/o intangibles, o desmaterializada, es decir, basada en mano de obra.

\section{Sucesión de empresa legal}

Esta modalidad de sucesión de empresas tiene lugar cuando se transmite una unidad productiva autónoma susceptible de ser explotada económicamente, como puede ser, la empresa en su totalidad, un centro de trabajo o una unidad productiva autónoma propiamente dicha.

Esta sería la modalidad que encaja literalmente en el art. 44 ET, que señala que "se considerará que existe sucesión de empresa cuando la transmisión afecte a una entidad económica que mantenga su identidad, entendida como un conjunto de medios organizados a fin de llevar a cabo una actividad económica, esencial o accesoria".

\footnotetext{
${ }^{7}$ SAN (orden social) de 27 de febrero de 2015 (Proc. 330/2014).

${ }^{8}$ STS (sala de lo social) de 9 de enero de 2019 (Rec. 108/2018).

9 SSTJUE de 24 de enero de 2002, Temco, Asunto 51/2000; de 20 de enero de 2011, Clece, Asunto 463/2009; de 20 de julio de 2017, Piscarreta Ricardo, Asunto 16/2016.
} 
Como señala la doctrina "es claro, en consecuencia, que la sucesión existe no solo cuando se transmite la empresa en su totalidad, sino que cabe transmitir únicamente un centro de trabajo o unidad productiva autónoma. Lo importante es que lo transmitido sea susceptible de explotación económica independiente y capaz de ofrecer bienes o servicios al mercado" 10 .

Para que tenga lugar esta sucesión de empresas, nuestro alto tribunal ha venido exigiendo la concurrencia de dos elementos, cuales son, el elemento objetivo y el elemento subjetivo. El elemento objetivo hace referencia al conjunto de elementos organizados, ya sean materiales o inmateriales, que son transmitidos y que permiten la continuación de la actividad económica, sin que la empresa subrogada tenga que aportar medios relevantes. El elemento subjetivo se refiere al cambio de titularidad, esto es, de la existencia de un acto jurídico de transmisión, ya sea, intervivos o mortis causa.

Dadas las situaciones de fraude de ley y de negocios nada transparentes, la doctrina da más relevancia al elemento objetivo que no al subjetivo. De cualquier forma, como se ha indicado, para determinar la existencia de una sucesión de empresas debe analizarse siempre caso por caso, valorando las circunstancias singulares y concretas de cada uno.

En este sentido, nuestro alto tribunal ha recalcado la necesidad de que el elemento material que se transmita constituya una unidad organizada y susceptible de ser explotada, pues "no puede apreciarse la sucesión cuando lo que se transmite no es (...) un conjunto organizativo, sino unos elementos patrimoniales aislados" $"$. Esta necesidad de que no se transmitan unos "elementos patrimoniales aislados" es una constante en la doctrina jurisprudencial, recalcándose la necesidad de que se transmita una "explotación empresarial viva", de tal forma que "por encima de las palabras utilizadas en la letra del precepto o en las sentencias interpretativas del mismo, lo que se trasluce de ellas es la exigencia de que se haya producido una transmisión de activos patrimoniales y personales, o sea, de elementos que permitan continuar una explotación empresarial "viva", que es lo que podría permitir hablar de la permanencia en su identidad" ${ }^{12}$. De esta forma no se ha admitido como sucesión de empresas un cambio de adjudicataria de servicios de contact center como consecuencia de la aportación de elementos materiales relevantes por parte de la nueva adjudicataria, pues "lo importante no es el coste de las inversiones en medios materiales sino la necesidad de los mismos"13. Ello significa que cuando lo que se transmite no permita la continuación de la actividad empresarial, no existirá sucesión de empresas.

La doctrina judicial comunitaria ${ }^{14}$ ha elaborado una teoría donde determina cuáles son los aspectos que deben ser evaluados de forma conjunta a efectos de determinar si existe o

\footnotetext{
${ }^{10}$ García-Perrote Escartín, Ignacio, Manual de Derecho del Trabajo, Valencia, Tirant lo Blanch, 2015, p. 610

${ }^{11}$ STS (sala de lo social) de 16 de julio de 2003 (Rec. 2343/2002).

${ }^{12}$ STS (sala de lo social) de 25 de febrero de 2002 (Rec. 4293/2000). En el mismo sentido, SSTS (sala de lo social) de 8 de junio de 2016 (Rec. 224/2015); (sala de lo social) de 14 de abril de 2016 (Rec. 35/2015). ${ }^{13}$ STS (sala de lo social) de 27 de enero de 2015 (Rec. 15/2014).

${ }^{14}$ SSTJUE (sala de lo social) de 9 de octubre de 2017, Securitas, Asunto 200/2016; (sala de lo social) de 20 de noviembre de 2003, Abler, Asunto 340/2001; (sala de lo social) de 24 de enero de 2002, Temco,
} 
no sucesión de empresa. Estos elementos son: el tipo de empresa o centro de actividad, la existencia de transmisión de bienes materiales, la transmisión de bienes inmateriales y su valor en el momento de la transmisión, si la nueva empresa se hace cargo de la mayoría de las personas trabajadoras, la transmisión de clientela, el grado de analogía de las actividades ejercidas antes de la transmisión y después de ella, y la duración de una posible suspensión de las actividades. Estos elementos deben ser evaluados en conjunto, y no aisladamente.

En este mismo sentido se pronuncia nuestro alto tribunal, señalando que deben valorarse dichos elementos de forma conjunta ${ }^{15}$. Pero además de la valoración global de todos estos elementos, es también fundamental, tener en cuenta el diferente peso o importancia de cada uno de ellos, de tal forma que, en función de la actividad de la empresa, existirá una prioridad diferente. Es decir, "la importancia respectiva que debe atribuirse a los distintos criterios propuestos por el TJCE para determinar la existencia de una transmisión en el sentido de la Directiva, criterios que ya fueron enunciados en la sentencia Spijkers (el tipo de empresa o centro de actividad de que se trate, el que se hayan transmitido o no elementos materiales como los edificios y los bienes muebles, el valor de los elementos inmateriales en el momento de la transmisión, el hecho de que el nuevo empresario se haga cargo o no de la mayoría de los trabajadores, el que se haya transmitido o no la clientela, así como el grado de analogía de las actividades ejercidas antes y después de la transmisión y la duración de una eventual suspensión de dichas actividades), y que varían, necesariamente, en función de la actividad ejercida, o incluso de los métodos de producción o de explotación utilizados en la empresa, en el centro de actividad o en la parte de centro de actividad de que se trate. De ahí la importancia de que los tribunales lleven a cabo una valoración conjunta de todos ellos, debiendo enjuiciarse cada caso según las circunstancias concurrentes"16.

Cuando se trata de una transmisión de unidad productiva autónoma, la doctrina judicial tiene declarado que esta debe preexistir a la transmisión y debe tener autonomía funcional suficiente. Se trata de un razonamiento que puede ser de utilidad para mantener la inexistencia de sucesión de empresa en aquellas unidades productivas autónomas encapsuladas o artificialmente generadas ad hoc antes de la transmisión para ser transmitidas vía sucesión de empresa.

\section{Sucesión de plantillas}

La sucesión de plantillas como supuesto de transmisión de empresas halla su origen en la doctrina judicial comunitaria. Este supuesto se aplica especialmente en aquellos sectores en los que la actividad descansa básicamente en la mano de obra, esto es, limpieza, seguridad, atención a domicilio de personas mayores, servicios auxiliares de vigilancia,

Asunto 51/2000; (sala de lo social) de 10 de diciembre de 1998, Sánchez Hidalgo, Asunto 173/1996 y 247/1996.

${ }^{15}$ SSTS (sala de lo social) de 9 de enero de 2019 (Rec. 108/2018); (sala de lo social) de 5 de marzo de 2013 (Rec. 3984/2011); (sala de lo social) de 7 de diciembre de 2011 (Rec. 4665/2010).

${ }^{16}$ Cavas Martínez, Faustino, "A vueltas con el concepto de traspaso de empresa en el Derecho Comunitario", Aranzadi Social, núm. 5, 2005, p. 6. 
embalaje, entre otras... En dichos supuestos, cuando se transmite una parte cualitativa y cuantitativamente considerable de personas trabajadoras, tiene lugar la sucesión de empresas. En este caso, la organización productiva es la plantilla de personas trabajadoras entendida como un conjunto de elementos personales organizados y "constitutiva de una entidad económica que mantiene su identidad. Este supuesto ha sido aceptado por la Sala Cuarta del TS en su sentencia de 27-10-2004 (aun suscitando en la misma ciertas "reservas", entre otras razones, "por el efecto de desincentivación de estas contrataciones y del establecimiento convencional de estas garantías, que acabarán privando de las oportunidades de empleo a los trabajadores que supuestamente se quiere proteger"), ya que la doctrina establecida por el Tribunal de Justicia de las Comunidades Europeas, al resolver cuestiones prejudiciales, es vinculante para el TS que ha de acatarla y ello no solo en el caso decidido por la sentencia que resuelve la cuestión prejudicial, sino con carácter general en todas aquellas que queden comprendidas en la interpretación que se establece" ${ }^{\prime 17}$.

Los requisitos para que tenga lugar la sucesión de empresa son, pues, por un lado, que la actividad empresarial se base, principalmente, en la mano de obra, sin que se requieran activos materiales o inmateriales relevantes, y por otro lado, que el cesionario asume una parte cualitativa y cuantitativamente relevante de personas trabajadoras de la empresa cedente $^{18}$.

Partiendo de estos requisitos, el TS ha elaborado un test para determinar si existe o no sucesión de plantillas, de tal forma que "la sucesión de plantillas se caracteriza por la presencia de las siguientes relaciones y circunstancias entre personas físicas y/o jurídicas: (a) una empresa contratista o adjudicataria de servicios sucede a la que desempeñaba anteriormente tales servicios por cuenta o a favor de un tercero; (b) la sucesión de contratas o adjudicaciones se ha debido a que la empresa o entidad comitente ha decidido dar por terminada su relación con la empresa saliente, encargando a la entrante servicios o actividades sustancialmente iguales a los que desarrollaba la contratista anterior; (c) la empresa entrante ha incorporado al desempeño de la contrata una parte importante, cualitativa o cuantitativamente, de la plantilla de trabajadores de la empresa saliente; y (d) el activo principal para el desempeño de los servicios es la mano de obra organizada u organización en el trabajo"19.

Así sucede pues cuando, en un caso de traspaso, se contratan a 14 de las 19 personas trabajadoras de la anterior empresa, y ello sin que la organización del trabajo experimentara una variación sustancial y sin que los servicios prestados fueran sustancialmente distintos ${ }^{20}$; o en un supuesto de cambio de adjudicataria en la contrata de auxiliares técnicos informáticos en los centros de urgencias del SAS, habiéndose contratado por la entrante a 70 de 87 personas trabajadoras ${ }^{21}$.

\footnotetext{
${ }^{17}$ STSJ de Madrid (sala de lo social) de 14 de julio de 2008 (Rec. núm. 2089/2008).

${ }^{18}$ SSTJUE (sala de lo social) de 24 de enero de 2002, Temco, Asunto 51/2000; (sala de lo social) de 10 de diciembre de 1998, Sánchez Hidalgo, Asunto 173/1996 y 247/1996.

${ }^{19}$ STS (sala de lo social) de 5 de marzo de 2013 (Rec. 3984/2011).

${ }^{20}$ STS (sala de lo social) de 5 de marzo de 2013 (Rec. 3984/2011).

${ }^{21}$ STS (sala de lo social) de 27 de abril de 2015 (Rec. 3984/2011).
} 
En relación con este test, se ha planteado cuál es el número de personas trabajadoras a partir del cual debe entenderse que existe una sucesión de plantillas. No existe una solución unánime, sino que dependerá de las circunstancias concretas, siendo la clave determinar si con las personas trabajadoras asumidas es posible proseguir o no con la actividad. En la práctica existe una cierta tendencia a pensar que cuando se asume al menos la mitad de las personas trabajadoras de la cesionaria, se estaría en dicho supuesto, pero, no es fácil establecer una cifra o número, pues debe estarse a cada caso. Para ello deberá valorarse si el número de personas trabajadoras que son transmitidas constituye un conjunto organizado y puede seguir realizando la actividad o parte de las actividades de forma estable, esto es, si mantiene su identidad aun después de su transmisión ${ }^{22}$. Es decir, si el número de personas trabajadoras, en relación con el conjunto de la plantilla que se precisa para la actividad, conforma un grupo cualitativamente significativo o relevante.

Debe señalarse que no es suficiente con tener en cuenta únicamente el aspecto cuantitativo o el aspecto cualitativo, pues este último deviene complementario en los casos en que, aun transferido un número significativo de la plantilla, se prueba su nula operatividad competencial por no haberse transferido a determinadas personas trabajadoras "clave". O al contrario, esto es, en el caso de que el elemento cuantitativo es poco importante, debe valorarse el aspecto cualitativo de competencias de las personas trabajadoras que son transmitidas, de tal forma que, aun cuando la empresa entrante asume una parte reducida de la plantilla, si entre ella se encuentran aquellas personas trabajadoras que ocupan puestos clave de la actividad, deber entenderse que se está ante una entidad económica que mantiene su identidad tras la transmisión y, por tanto, ante una sucesión de empresa.

De este modo, se ha determinado que existe sucesión de empresas cuando se contratan a 70 de 87 personas trabajadoras ${ }^{23}$; a 10 de $14^{24}$, a 23 de $33^{25}$, e incluso, a 7 de 13 personas trabajadoras $^{26}$, o a 42 de $85^{27}$. En palabras de la doctrina judicial: "concurren las circunstancias que dan lugar a lo que se ha llamado subrogación por sucesión de plantillas. En efecto, se ha producido una sucesión en la actividad de prestación de los mismos servicios auxiliares en determinados hipermercados y la empresa entrante ha asumido una gran parte de la mano de obra (más del 70 por 100) de la anterior, trabajadores a quienes ha empleado en los mismos hipermercados en los que venía trabajando, sin que la nueva empleadora, aparte de algún trabajador propio, haya aportado elementos materiales que fuesen necesarios para el desarrollo de la actividad, lo que evidencia que lo esencial para los "servicios auxiliares" que presta es la cualificación y experiencia profesional de los

\footnotetext{
22 Sánchez-Urán Azaña, María Yolanda, "Sucesión de empresa por sucesión de plantilla: conflictos interpretativos derivados de una doctrina controvertida", Revista Española de Derecho del Trabajo, núm. 214, 2018 (versión on line)

${ }^{23}$ STSJ de Canarias (sala de lo social) de 28 de febrero de 2007 (Rec. 197/2004).

${ }^{24}$ STSJ de Galicia (sala de lo social) de 28 de septiembre de 2005 (Rec. 3486/2005).

${ }^{25}$ STSJ de Castilla y León (sala de lo social) de 11 de julio de 2007 (Rec. 951/2007).

${ }^{26}$ SSTSJ de Madrid (sala de lo social) de 14 de enero de 2009 (Rec. 5549/2008); Madrid (sala de lo social) de 22 de diciembre de 2008 (Rec. 5066/2008).

${ }^{27}$ STSJ de Castilla y León (sala de lo social) de 4 de julio de 2007 (Rec. 1089/2007).
} 
trabajadores que emplea y no la aportación de elementos materiales necesarios para la producción, máxime cuando tal aportación no consta"28.

Además, debe tenerse en cuenta que, a diferencia de la anterior doctrina que estimaba que no existía sucesión de empresa cuando se asume una parte de la plantilla en virtud de lo previsto en convenio colectivo, no transmitiéndose, por tanto, los elementos objetivos materiales de la contrata, ahora la doctrina jurisprudencial entiende que sí existe dicha sucesión. Es decir, con anterioridad el TS estimaba que "para el desarrollo de una actividad como la del Contact Center, que necesita de inmuebles, teléfonos, aparatos informáticos etc., que son imprescindibles para su desarrollo como el presente en la que la nueva contratista no se ha limitado a continuar con la actividad desempeñada por la anterior asumiendo para ello la totalidad o parte de su plantilla, sino que ha puesto sus propias instalaciones, sus medios técnicos y su know how (saber hacer como empresa), lo que impide estimar que haya existido sucesión de plantillas, pues estas circunstancias evidencian una situación distinta que justifica la inaplicación del artículo 44 del ET, o lo que es lo mismo, se trata de una sucesión de contratas y no sucesión de empresa"29.

Sin embargo, en la actualidad, la sucesión de plantilla que es consecuencia de lo previsto en el convenio colectivo no afecta al modo en que deba resolverse la transmisión. Es decir, que la empresa entrante se subrogue en los contratos de trabajo de una parte significativa del personal adscrito por mandato del convenio no afecta al hecho de que la trasmisión pueda referirse a una entidad económica. En sectores donde la mano de obra constituye el elemento principal de la actividad empresarial es posible que el conjunto de personas adscritas a la actividad equivalga a la unidad económica cuyo cambio de titularidad activa la subrogación ${ }^{30}$.

\section{Sucesión convencional}

La sucesión de empresas ex convenio o también denominada sucesión de contratas tiene lugar cuando el convenio colectivo aplicable a la empresa cedente y a la empresa cesionaria impone a esta última la obligación de subrogarse en las personas trabajadoras adscritas a la contrata.

\footnotetext{
${ }^{28}$ STS (sala de lo social) de 12 de marzo de 2015 (Rec. 1480/2014).

${ }^{29}$ SSTS (sala de lo social) de 15 de julio de 2013 (Rec. 1377/2013); (sala de lo social) de 27 de enero de 2015 (Rec. 15/2014). Sin embargo, la STS (sala de lo social) de 22 de septiembre de 2016 (Rec. 1438/2014), señala que prima el capital humano, pues "es pacífico que en ningún caso ha habido transmisión de medios patrimoniales por lo que nos hallamos en presencia de una contrata en la que el peso de su explotación y rentabilidad radica exclusivamente en la mano de obra. Esa circunstancia debería conducirnos a la aplicación de la doctrina del Tribunal de Justicia de la Unión Europea y a su dicotomía en función del volumen de plantilla anterior incorporado por la nueva adjudicataria (...) En suma la incorporación de una parte sustancial o cuantitativamente elevada de la plantilla anterior hace que en el supuesto de cambio de titular concurra el elemento material necesario, aun cuando sea humano, para que la actividad productiva se conduzca de manera autónoma daría lugar así a la sucesión empresarial el artículo 44 del Estatuto de los Trabajadores. Hasta ahí, la doctrina comunitaria deja en manos de la empresa entrante, en función de que decida asumir o no el todo o mayor parte de la plantilla, la aplicabilidad de la figura sucesoria".

${ }^{30}$ STS (sala de lo social) de 27 de septiembre de 2018 (Rec. 2747/2016). En el mismo sentido, STS (sala de lo social) de 8 de enero de 2019 (Rec. 2833/2016).
} 
Esta institución jurídica tiene como objetivo garantizar la subrogación de las personas trabajadoras en los supuestos en que la figura ex art. 44 ET, esto es, la sucesión de empresas no va a tener lugar o es de dudosa aplicación. Se trata de proteger la continuidad de las relaciones laborales, de evitar que las personas trabajadoras se vean abocadas al desempleo en aquellos casos en los que no es aplicable el art. 44 ET, ya sea porque no existe una transmisión de elementos materiales entre la empresa cedente y cesionaria, o porque no existe una trasmisión de elementos inmateriales... De esta forma, es el propio convenio colectivo el que prevé una mejora respecto del régimen legal y cubrir el vacío del ET.

En palabras de nuestro alto tribunal "así, en nuestro Derecho Colectivo, los sectores que regulan la subrogación en los Convenios Colectivos son asistencia, atención, diagnóstico, rehabilitación y promoción de minusválidos; asistencia en tierra en aeropuertos (handling); atención a las personas dependientes y desarrollo de la promoción de la autonomía personal; captación, elevación, conducción, tratamiento, depuración y distribución de aguas; construcción; contact center; contratas ferroviarias; empresas concesionarias y privadas de aparcamientos de vehículos; entrega domiciliaria; hostelería; instalaciones deportivas; juego del bingo; limpieza de edificios y locales; limpieza pública, viaria, riegos, recogida, tratamiento y eliminación de residuos, limpieza y conservación de alcantarillado; mantenimiento de cabinas, soportes y teléfonos de uso público; puertos de Estado y autoridades portuarias; regulación de estacionamiento limitado de vehículos en la vía pública; reparto sin direccionar; seguridad; transportes de enfermos y accidentados en ambulancias. Además, existe una relación de sectores que regulan la subrogación en sus Convenios Sectoriales autonómicos y/o provinciales”.

Debe tenerse presente que esta figura jurídica no puede recogerse en un convenio colectivo de empresa, sino que únicamente puede ser regulada en un convenio sectorial, pues, es lógico que, si estuviera en un convenio colectivo de empresa, por su ámbito de aplicación, no podría imponerse a la nueva adjudicataria, fuera de su alcance. Además, la subrogación en la plantilla no es una de las materias sobre las que el art. 84.2 ET establece la prioridad aplicativa del convenio colectivo de empresa. Como señala la doctrina "la eliminación de la regla de subrogación convencional de personal por un convenio de empresa concluido con posterioridad a otro de ámbito superior que la establece (...) al tratarse de una materia no susceptible de ser subsumida en el listado legal, quedaría sometida a la regla general de concurrencia y prohibida, por tanto, cualquier afectación invasiva de lo pactado que estaría incursa en la citada ineficacia" 31 .

Por otro lado, esta subrogación vía convenio colectivo suele fijar determinados requisitos para que una persona trabajadora pueda ser subrogada, tales como, que cuente con una determinada antigüedad, o contar con una determinada habilitación, o realizar una previa selección.... Además, es bastante frecuente, exigir a la empresa saliente que cumpla con una serie de requisitos previstos en el convenio, como puede ser, la entrega de una determinada documentación, el cumplimiento de las obligaciones laborales y de

\footnotetext{
${ }^{31}$ Mercader Uguina, Jesús Rafael, La regulación del Mercado laboral. Un análisis de la Ley 3/2012 y de los aspectos laborales del Real Decreto-Ley 20/2012, Valladolid, Lex Nova, 2012.
} 
Seguridad Social,... de tal modo que si se incumplen, no tendrá lugar ninguna subrogación, y la empresa entrante no tendrá ninguna obligación al respecto. Así sucede cuando, por ejemplo, se incumple la entrega de la documentación establecida en el convenio, declarando el órgano judicial que "hemos indicado con reiteración que si la empresa saliente no hubiera incumplido de manera suficiente los deberes que le impone el convenio colectivo no se produce transferencia alguna hacia la empresa entrante, siendo la empresa incumplidora de esa obligación la responsable de las consecuencias perjudiciales que sobrevengan al trabajador afectado y más en concreto del despido en el caso de que se haya producido, y no cabe invocar en contra de ello la vulneración del derecho del trabajador a la estabilidad en el empleo porque dicho derecho está asegurado en cuanto persiste, en estos supuestos la vigencia del contrato de trabajo con la empresa saliente" 32 .

Tampoco se estima que tiene lugar esta sucesión cuando no existe una nueva empresa titular de la contrata, pues "como señala igualmente esta Sala IV, TS resolviendo supuesto sustancialmente idéntico (Rcud. 1584/14): [B] arrendó a [A], con opción obligatoria de compra, el negocio geriátrico (la industria), asumiendo [B] y subrogándose en los trabajadores que $[\mathrm{A}]$ tenía destinados en la residencia, pero el referido servicio, tanto formal como materialmente, continuó realizándose por [C], no sólo porque así ha de entenderse de la ausencia de denuncia en plazo del propio contrato de prestación de servicio entre $[\mathrm{B}]$ y $[\mathrm{C}]$, en el que formalmente se estipuló la prórroga anual automática al vencimiento del primer trienio, sino también porque, materialmente, tal como se desprende de la relación fáctica, [C], al menos hasta que [B] comenzó a ocuparse con sus propios medios de los servicios de limpieza, lavandería y mantenimiento de la residencia y otra contrata [D], hizo lo propio con los de restauración-hostelería: siguió prestando aquellas mismas actividades que constituían el objeto de su contrato de prestación de servicios. Es decir, partiendo de que, en el caso, la contrata entre [B] y [C] abarcaba exclusivamente el arrendamiento de un determinado servicio, lo que comporta que, no transmitido este a la nueva titular del negocio o industria ([B]), sin que tampoco conste el traspaso de una organización de medios materiales y humanos, o sólo humanos en una proporción significativa (...) habrá de ser la propia entidad titular de aquel contrato de prestación del servicio ([C]), que se mantuvo al no haber denunciado en plazo, quien corra con las consecuencias de la declaración de improcedencia”.

Por último, debe tenerse en cuenta que, aunque esta sucesión convencional únicamente conlleva la obligación de subrogación por la empresa entrante de la plantilla de la saliente $^{33}$, sin embargo, dicha subrogación convencional puede comportar la existencia de una sucesión de empresas ex art. 44 ET, esto es, una sucesión de empresa por sucesión

\footnotetext{
${ }^{32}$ STS (sala de lo social) de 12 de febrero de 2014 (Rec. 2028/2012). En similares términos, SSTS (sala de lo social) de 27 de abril de 2016 (Rec. 329/2015); (sala de lo social) de 19 de mayo de 2015 (Rec. 358/2014); (sala de lo social) de 16 de junio de 2015 (Rec. 1784/2014).

${ }^{33}$ STS (sala de lo social) de 27 de abril de 2016 (Rec. 329/2015), que señala que "la nueva empresa adjudicataria del servicio de seguridad que tiene obligación de subrogarse en los trabajadores de la anterior empresa por mandato del artículo 14 de convenio colectivo, lo debe hacer con los requisitos y límites que el mismo establece, de manera especial, sin responder de las deudas contraídas por la empresa adjudicataria anterior con sus trabajadores antes de la asunción de la contrata por la nueva empresa".
} 
de plantilla. De esta forma, cuando la empresa entrante contrate a una parte cuantitativa y cualitativamente considerable de personas trabajadoras de la empresa saliente, y si su actividad descansa fundamentalmente en la mano de obra, podría tener una sucesión de plantillas. Además de la subrogación de personal, también se aplicaría el régimen jurídico ex art. 44 ET en relación con la responsabilidad solidaria de las obligaciones laborales y de Seguridad Social. Es decir, como se ha indicado, nuestro alto tribunal, en aras a unificar la doctrina jurisprudencial con la comunitaria, rectificó su anterior doctrina para pasar a entender que existe una transmisión de empresas encuadrable en el art. 44 ET cuando la sucesión de contratas va acompañada de la transmisión de una entidad económica entre las empresas saliente y entrante, siempre que en dichas actividades la mano de obra constituya un factor esencial y se produzca una asunción de una parte relevante del personal adscrito a la contrata, pues el hecho de que la asunción de una parte relevante de la plantilla derive de lo preceptuado en el convenio colectivo no impide la aplicación de dicha doctrina ${ }^{34}$.

Así sucede cuando se declara que existe sucesión de empresa entre la empresa entrante y la empresa contratista entrante del servicio de seguridad de un Museo Público, en tanto en cuanto la actividad de vigilancia de las instalaciones del Museo descansa esencialmente en la mano de obra, y la empresa entrante se ha hecho cargo de toda la plantilla ${ }^{35}$. Es decir, "lo que no debemos hacer es seguir abordando el problema atendiendo a la causa de esa continuidad significativa de contratos de trabajo (el mandato convencional). Por el contrario, son los efectos derivados de la previsión del convenio (asunción de una parte significativa de la plantilla) los que deben valorarse para determinar si hay sucesión de empresa"36.

\section{Sucesión por pliegos}

La sucesión vía pliegos tiene como objetivo cubrir los espacios a los que no puede llegar la sucesión de empresas del art. 44 ET, y otorgar a las personas trabajadoras adscritas a la contrata la estabilidad en el empleo. Dicha estabilidad se instrumenta en los pliegos de condiciones particulares de la empresa principal o la Administración correspondiente, en los que se incluye la obligación de la nueva empresa concesionaria de contratar al personal de la anterior adjudicataria ${ }^{37}$. Es muy similar al anterior supuesto, pero en vez de venir previsto en el convenio colectivo, se recoge en el pliego de condiciones particulares.

Puede suceder, incluso, que esta subrogación no venga recogida propiamente en el pliego de condiciones particulares, sino en un anexo al mismo en el que la Administración comunica a la nueva adjudicataria los nombres y antigüedad de las personas trabajadoras adscritas al servicio para que proceda a su subrogación.

\footnotetext{
${ }^{34}$ STS (sala de lo social) de 27 de septiembre de 2018 (Rec. 2747/2016).

${ }^{35}$ STJUE (sala de lo social) de 11 de julio de 2018, Somoza Hermo, Asunto 60/2017. Doctrina asumida por la STSJ de Galicia (sala de lo social) de 26 de julio de 2018 (Rec. 2310/2016).

${ }^{36}$ STS (sala de lo social) de 27 de septiembre de 2018 (Rec. 2747/2016).

${ }^{37}$ Martínez Saldaña, David, (Coord.), La sucesión de empresas, Cizur Menor, Lex Nova, 2016, p. 85.
} 
Obviamente, a diferencia de la sucesión de empresas ex art. 44 ET, o de la sucesión convencional, esta sucesión constituye un contrato entre la Administración y las empresas adjudicatarias, esto es, la entrante y la saliente. La subrogación que viene recogida en los pliegos requiere de la aceptación de las personas trabajadoras, de tal forma, que si no la aceptan, no podrá ser efectiva. De ahí que la doctrina judicial ${ }^{38}$ haya señalado que esta subrogación constituye, en el fondo, un supuesto de novación contractual que requiere del consentimiento de la persona trabajadora.

La doctrina jurisprudencial diferencia entre aquella concesión administrativa que lleva aparejada la entrega al concesionario de la infraestructura u organización empresarial básica para la explotación del servicio; y aquella otra en la que, al no concurrir la puesta a disposición de los elementos patrimoniales fundamentales, faltan los requisitos necesarios para apreciar una sucesión de empresa regulada por la norma estatutaria, aunque las regulaciones sectoriales puedan introducir medidas de las relaciones laborales. Es decir, la subrogación por pliegos puede ser, o bien el resultado de una sucesión legal de empresa conforme al art. 44 ET, o bien por consecuencia de lo dispuesto en el convenio colectivo de aplicación a las empresas concesionarias del servicio cuando no hay transmisión de empresa ${ }^{39}$.

\section{Sucesión de empresa por transmisión de clientela}

Esta emergente modalidad de sucesión de empresa, esto es, por sucesión de clientela, parece que va consolidándose entre nuestra doctrina judicial. Esta modalidad halla su origen en la doctrina judicial comunitaria, y como es regla general, va instalándose entre nuestra doctrina. Como señala la misma 40 "el propio TJUE establece otros factores a tener en cuenta, como la duración de la suspensión de la actividad o la transmisión de la clientela. Así pues, a nuestro juicio, el Tribunal Supremo no debería olvidar estos otros factores. En concreto, la clientela o "fondo de comercio" es un factor que en el caso de la sucesión de contratas no es valorado, normalmente, por la jurisprudencia siendo este crucial para cualquier empresa. Sobre todo en aquellas empresas que no necesitan inversión patrimonial (es decir, capital), el principal activo de esta será su clientela la cual tendrá que ser valorada necesariamente para saber si ha habido sucesión de empresas (...) Profundizando más en la importancia de la clientela para una empresa, se comprueba que en el concreto supuesto de una sucesión de contratas lo que siempre se transmitirá será la clientela, puesto que por la propia naturaleza de la sucesión de contratas lo que siempre se sucede es el cliente principal, es decir, el contratante, el cual antes era el cliente de la empresa saliente y ahora lo será de la entrante. Así pues, en toda contrata, la nueva empresa estará adquiriendo la clientela de la anterior contratista, siendo este un elemento que se transmite siempre en estos supuestos y, que dada su importancia en las empresas, debe conducir en muchos casos a la aplicación del art. 44 del ET".

\footnotetext{
${ }^{38}$ STS (sala de lo social) de 12 de diciembre de 2007 (Rec. 3994/2006).

${ }^{39}$ Fernández Nieto, Liviana Aurora, "Subrogación y externalización de servicios en la Jurisprudencia de la Sala de lo Social del Tribunal Supremo (2017)”, Diario La Ley, núm. 9115, 2018 (versión on line)

${ }^{40}$ Sala Franco, Tomás; López Terrada, Eva; Todolí Signes, Adrián, Jurisprudencia Social a debate, Valencia, Tirant lo Blanch, 2015 (versión on line)
} 
La sucesión de empresa por sucesión de clientela tiene lugar en aquellos casos en los cuales entre la empresa saliente y la cedente no se produce ninguna cesión de elementos materiales, ni tampoco de la plantilla, sino que el elemento determinante es la clientela que es asumida por la empresa entrante.

Entre nuestra doctrina judicial no se contaban con pronunciamientos que asumieran que la sucesión de empresa podía tener lugar cuando únicamente existía una sucesión de clientela, pues en los otros casos en los que se ha hecho referencia a la clientela, ha sido siempre relacionándolo con otros indicios, tales como la transmisión de la plantilla, del equipamiento o elementos materiales o intangibles. Así, se señala que "en el presente supuesto no ha quedado acreditado que se haya producido transmisión alguna, ni de elementos patrimoniales precisos para la realización de la actividad, ni de la clientela, ni cabe hablar de "sucesión de plantillas" al tratarse de una "actividad materializada", por lo que no apreciamos la existencia de sucesión de empresa"41. De hecho, en algunos casos se negaba que la transmisión de clientela fuera indicio de la sucesión de empresa, pues se consideraba que no existía "transmisión de una entidad económica que mantenga su identidad, ni asunción de plantilla y sin que, en este caso, la coincidencia en la clientela, suponga la cesión de la misma"42, o que "no se desprende que se haya producido la transmisión de elementos materiales o personales ni tampoco las características de la actividad determinan que la clientela es un elemento definidor que permita concluir que nos encontremos ante una entidad económica que mantenga su entidad, constando solamente una coincidencia de dos clientes" ${ }^{\prime 3}$.

El TJUE ${ }^{44}$ analizó un caso en el que una entidad bancaria cesa en sus actividades de inversión comunicando a sus clientes la posibilidad de dirigirse a Alta Invest para que esta entidad siguiera gestionando sus títulos, y ofreciéndoles condiciones particulares para favorecer dicha continuidad. Como consecuencia, más del $90 \%$ de los clientes de la entidad bancaria aceptaron la cesión a favor de Alta Invest. Por su parte, las personas trabajadoras que venían prestando servicios en la entidad bancaria fueron despedidas y reubicadas en la empresa.

El TJUE parte, como se ha señalado, de que han de analizarse todas las circunstancias concurrentes. Así debe examinarse el tipo de empresa o de centro de actividad de que se trate, la relevancia de los elementos materiales cedidos entre ambas entidades, el valor de los elementos inmateriales en el momento de la transmisión, el hecho de que la nueva empresa se haga cargo o no de la mayoría de la plantilla, el hecho de que se haya cedido o no clientela, así como el grado de analogía de las actividades ejercidas antes y después de la transmisión, y la duración de una eventual suspensión de dichas actividades. En dicho caso, el órgano judicial comunitario estima que no se produce una cesión de

\footnotetext{
${ }^{41}$ STSJ de Andalucía (sala de lo social) de 17 de julio de 2020 (Rec. 926/2019). En similares términos, STSJ de Madrid (sala de lo social) de 29 de noviembre de 2017 (Rec. 1039/2017).

${ }^{42}$ STSJ de Galicia (sala de lo social) de 24 de octubre de 2019 (Rec. 3186/2019).

${ }^{43}$ STSJ de Canarias (sala de lo social) de 21 de octubre de 2019 (Rec. 208/2019).

${ }^{44}$ STJUE (sala de lo social) de 8 de mayo de 2019, Dodic, Asunto 194/2018. En similares términos, se pronuncian las SSTJUE (sala de lo social) de 26 de noviembre de 2015, ADIF, Asunto 509/2014; (sala de lo social) de 20 de noviembre de 2013, Abler, Asunto 340/2001.
} 
elementos materiales, ni tampoco una sucesión de plantilla, pues las personas trabajadoras han sido reubicadas en la entidad bancaria, pero sí ha tenido lugar una sucesión de clientela. En base a dicha transmisión de clientela, estima que existe una transmisión de empresa.

Como asunción de dicha doctrina, nuestros órganos judiciales también han tenido oportunidad de pronunciarse al respecto. Así el TSJ País Vasco ${ }^{45}$ enjuicia el caso de una estación de autobuses del Ayuntamiento de Bilbao donde existe una cafetería. Tras las obras de construcción de una nueva estación en el mismo terreno en el que estaba, la empresa concesionaria suscribe un contrato de arrendamiento de local para cafetería con una empresa diferente a la anterior, de tal forma que la concesionaria resuelve el contrato de arrendamiento con la anterior empresa y se da de baja a los trabajadores de la cafetería.

El TSJ País Vasco recurre a la doctrina judicial comunitaria del Asunto Dodic y, frente al argumento de que no existe una "cesión" propiamente dicha de clientela, ya que ello exige un acuerdo de voluntades de la clientela y la empresa entrante", expone que en este caso la cesión de clientela es evidente, pues la transmisión no depende del consentimiento de los clientes, ya que se trata de clientela "cautiva".

El elemento determinante para entender que existe una sucesión de empresas es la transmisión de clientela, aunque también son indicios relevantes el lugar de ubicación de la cafetería y la continuación de la actividad empresarial, ya que la cafetería está ubicada dentro de la estación de autobuses y una empresa cierra un día y la otra empresa abre el día siguiente.

Estima que existe "la sucesión legal de empresas constituida por la transmisión empresarial. Entendemos que en el negocio de cafetería de una estación de autobuses el valor predominante es su activo intangible integrado por la clientela, en este caso es indudable que ese activo se ha transmitido claramente de una empresa explotadora de la cafetería a la otra, y ello por la naturaleza y ubicación del negocio, situado (antes y ahora) dentro de la estación de autobuses y que por ello atendía y sigue atendiendo predominantemente a los viajes y sus acompañantes. La cafetería de una estación depende fundamentalmente de los clientes, por eso es su principal valor. Una empresa puede tener muy buenos productos e instalaciones, pero si los clientes no acuden regularmente no tiene ningún valor, por ello en ese concreto caso al transmitirse la clientela se transmite la empresa pues es el activo más importante". Por tanto, "al trasladarse la estación, aunque se cierre una cafetería y se abra otra, hay identidad empresarial porque la cafetería sigue estando dentro de la estación de autobuses y se trasladan los clientes, es decir, se han transmitido los elementos suficientes y más importantes que permiten la continuidad del negocio por el nuevo titular". No es relevante pues la inversión realizada por la nueva empresa para acondicionar el local, ni que tampoco haya posteriormente una nueva cafetería en la nueva estación.

En otro caso -relativo a una actividad de restauración-, la doctrina judicial comunitaria estimó que "la restauración colectiva no puede considerarse como una actividad que se

45 STSJ de País Vasco (sala de lo social) de 7 de enero de 2021 (Rec. 1453/2020). 
base esencialmente en la mano de obra, en la medida en que se exigen unos equipos importantes. Como lo señala la Comisión, en el asunto principal, Sodezho se hizo cargo de los elementos materiales indispensables para la actividad de que se trata -a saber, los locales, el agua y la energía así como los equipos, pequeños y grandes (en particular los elementos fijos necesarios para la preparación de las comidas y las lavadoras)-. Además, la situación controvertida en el litigio principal se caracteriza por la obligación, expresa y esencial, de preparar las comidas en la cocina del hospital y, por lo tanto, de hacerse cargo de dichos elementos materiales. La transmisión de los locales y de los equipos, puestos a disposición por el hospital, que es indispensable para la preparación y la distribución de las comidas a los pacientes y al personal del hospital, basta para caracterizar, en estas circunstancias, la transmisión de la entidad económica. Además, es evidente que el nuevo adjudicatario se ha hecho cargo necesariamente de la clientela de su antecesor, por tener esta carácter cautivo" 46 .

Sin embargo, en mi opinión, y el de un sector doctrinal ${ }^{47}$, es bastante complejo entender que en este caso en el que únicamente existe una transmisión de clientela, que a la postre, se trata de una clientela cautiva, existe una transmisión de empresa, cuando queda evidenciado que la empresa entrante llevó a cabo una remodelación considerable del local para poner en marcha el negocio, remodelación que por su alta inversión, supuso una desnaturalización de lo que existía con anterioridad a la transmisión de empresa. De cualquier forma, como indica nuestro alto tribunal, "lo importante no es el coste de las inversiones en medios materiales, sino la necesidad de los mismos, ya que, la importancia de los factores que intervienen en la producción no se mide en términos cuantitativos, sino cualitativos, esto es, atendiendo a la necesidad de los mismos para el funcionamiento de la actividad, necesidad que en este caso es evidente porque sin las inversiones hechas por la nueva contratista y demás materiales puestos por ella los trabajadores que contrató de la antigua no habrían podido prestar el servicio que requería la actividad por falta de instalaciones y demás medios materiales" ${ }^{48}$.

En definitiva, deben ponderarse todos los elementos concurrentes, y caso por caso, no pudiéndose extraer una regla general y universal, pues, en función del tipo de empresa, en función de la actividad a que se dedique, y de los elementos anteriormente señalados, se podrá concluir si existe o no una sucesión de empresa.

\section{A modo de reflexión final}

Como se ha indicado, la sucesión de empresas, a pesar de su tímida regulación legal, tiene una amplia base judicial. Han sido la doctrina jurisprudencial y judicial, las que, a partir

\footnotetext{
46 STJUE (sala de lo social) de 20 de noviembre de 2003, Abler, Asunto 340/2001.

${ }^{47}$ Beltrán de Heredia Ruiz, Ignasi, "Cafetería de terminal de autobuses: la asunción de clientela puede ser suficiente para la subrogación de empresa (STSJ País Vasco 7/1/21)”, Una mirada crítica a las relaciones laborales [blog]. Disponible en https://ignasibeltran.com/2021/05/05/cafeteria-de-terminal-de-autobusesla-asuncion-de-clientela-puede-ser-suficiente-para-la-subrogacion-de-empresa-stsj-pais-vasco-7-1-21/.

${ }^{48}$ SSTS (sala de lo social) de 9 de enero de 2019 (Rec. 108/2018); (sala de lo social) de 27 de enero de 2015 (Rec. 15/2014).
} 
de las peculiaridades propias de cada caso enjuiciado, han ido perfilando las características configuradoras de esta institución.

Además, tarea fundamental también es la realizada por la doctrina judicial comunitaria, la que a raíz de la interpretación de la Directiva comunitaria, va fijando unas directrices que van siendo asumidas por nuestra doctrina.

Más allá de los clásicos supuestos de sucesión de elementos materiales o bienes intangibles, se había planteado la posibilidad de que, en ciertas actividades "desmaterializadas", el elemento de transmisión fuera únicamente la plantilla para considerar que existía una transmisión de empresa, y, por tanto, aplicar el régimen legal correspondiente.

Sin embargo, en los últimos tiempos surge una nueva posibilidad de transmisión, cuyo elemento clave lo constituye la clientela. No existe aún una doctrina totalmente consolidada y clara al respecto, por lo que habrá que esperar a los próximos pronunciamientos judiciales. Pero no es cuestión nada fácil, dilucidar y determinar cómo debe aplicarse la sucesión de clientela como supuesto de transmisión de empresa.

\section{Bibliografía}

Beltrán de Heredia Ruiz, Ignasi, "Cafetería de terminal de autobuses: la asunción de clientela puede ser suficiente para la subrogación de empresa (STSJ País Vasco 7/1/21)", Una mirada crítica a las relaciones laborales [blog]. Disponible en https://ignasibeltran.com/2021/05/05/cafeteria-de-terminal-de-autobuses-la-asuncionde-clientela-puede-ser-suficiente-para-la-subrogacion-de-empresa-stsj-pais-vasco-7-1$21 \%$

Cavas Martínez, Faustino, "A vueltas con el concepto de traspaso de empresa en el Derecho Comunitario", Aranzadi Social, núm. 5, 2005.

Fernández Nieto, Liviana Aurora, "Subrogación y externalización de servicios en la Jurisprudencia de la Sala de lo Social del Tribunal Supremo (2017)”, Diario La Ley, núm. 9115, 2018 (versión on line)

García-Perrote Escartín, Ignacio, Manual de Derecho del Trabajo, Valencia, Tirant lo Blanch, 2015.

Martínez Saldaña, David, (Coord.), La sucesión de empresas, Cizur Menor, Lex Nova, 2016.

Mercader Uguina, Jesús Rafael, “Comentario al artículo 44 ET”, en Cruz Villalón, Jesús, García-Perrote Escartín, Ignacio, Goerlich Peset, José María, Mercader Uguina, Jesús Rafael, (Dirs.), Comentarios al Estatuto de los Trabajadores, Valladolid, Lex Nova, 2014. 
Mercader Uguina, Jesús Rafael, La regulación del Mercado laboral. Un análisis de la Ley 3/2012 y de los aspectos laborales del Real Decreto-Ley 20/2012, Valladolid, Lex Nova, 2012.

Sala Franco, Tomás; López Terrada, Eva; Todolí Signes, Adrián, Jurisprudencia Social a debate, Valencia, Tirant lo Blanch, 2015 (versión on line)

Sánchez-Urán Azaña, María Yolanda, "Sucesión de empresa por sucesión de plantilla: conflictos interpretativos derivados de una doctrina controvertida", Revista Española de Derecho del Trabajo, núm. 214, 2018 (versión on line)

Sempere Navarro, Antonio Vicente, "Un comentario al art. 44 del Estatuto de los Trabajadores", Aranzadi Social, núm. 9, 2014. 